\title{
Analysis of the Current Situation of Supply Chain Finance and Risk Control-Based on the Perspective of Commercial Banks
}

\author{
Danting Zheng*
}

Ningbo Tech University, Ningbo 315000, Zhejiang, China. E-mail: 912020827@qq.com

Abstract: China's economic policy system has been greatly adjusted up till the present moment. The scale of small and medium-sized enterprises mortgage lending is limited, but the demand for funds is increasing, and the need for core enterprises to grow and develop is increasing, supply chain finance effectively solved the needs of the above enterprises. Supply chain finance promotes the development of trade and commerce business, reduces financing risk, become a new business of commercial banks. Compared to traditional banking business, it reduces certain credit risk and improves the utility of funds, but China's supply chain financial system is not perfect enough, with a certain degree of system operation risk. Focus on the analysis of supply chain finance status quo, analyze China's supply chain development status and prospects, assess and analyze the risk, and do a good job of risk prevention and control. As an important part of the supply chain, commercial banks are necessary to pay attention to various risk points to the supply chain of the financing subject. Avoiding and reducing the risk of supply chain finance business are the top priority issues required to be solved for commercial banks.

Keywords: Supply Chain Financing; Commercial Banks; Risk Control

At present, affected by the international economic environment, China's economic growth is expected to be $1.9 \%$, the growth rate has slowed down. The development of various industries has been affected to some degree, Chinese government has spotted relative policies to deal with the problem. The Suggestion on Standardizing the Development of Supply Chain Finance to Support the Stable Cycling and Upgrading of Supply Chain Industry provides policy support for the development of supply chain finance in China. The financing demand of small and medium-sized enterprises is strong, and the digitalization process of commercial banks has entered a new stage of development. China's supply chain finance has entered a new phase of intelligence and digitalization. Based on strong policy support and the need for corporate finance, supply chain finance has gradually become the key direction in the transformation of commercial banking business. Its essence is to activate the inventory and accounts receivable of enterprises in the industrial chain. It has the characteristics of weakening asset mortgage, strengthening the authenticity of transaction background, improving the self-compensation of the source of repayment and enhancing the counter-guarantee of the core enterprise. Supply chain finance is highly in match with the financing conditions of small and medium-sized enterprises, which is beneficial to solve the financing constraints caused by the lack of real estate mortgage for these enterprises and increase the possibility of bank investment.

\section{The present situation of supply chain finance development}

Copyright $\odot 2020$ Danting Zheng

doi: $10.18282 / f f . v 9 i 4.1533$

This is an open-access article distributed under the terms of the Creative Commons Attribution Non-Commercial License

(http://creativecommons.org/licenses/by-nc/4.0/), which permits unrestricted non-commercial use, distribution, and reproduction in any medium, provided the original work is properly cited. 


\subsection{Supply chain finance business}

Currently, "Supply chain finance mainly includes accounts receivable financing model, inventory pledge financing model and advance payment financing model"[1]. Based on these models, a variety of deformed financing models are extended.

\subsection{The current situation and prospect of supply chain finance}

Supply chain finance is in the initial stage of development in China, but it is developing rapidly because of the advantages like convenient payment mechanism, high financing efficiency and good risk control. However, supply chain finance presents an unbalanced development trend in China, which has significant regional differences. High-income regions are highly affected by supply chain finance while compared to low-income regions. Due to the economic situation and the deterioration of the business environment, commercial banks shrink the credit cycle. But supply chain finance shows an upward trend, which indicates the characteristics of strong financing demand for small and medium-sized enterprises, and the trend of supply chain business has gradually become the main business of commercial banks. Due to the maturity of cloud computing, big data and internet technology, the development of online supply chain finance will accelerate ${ }^{[2]}$.

\section{The supply chain finance risk of commercial banks}

\subsection{Operational risks of supply chain finance}

\section{Personnel Factors}

The significant economic losses resulted from the unprofessional or moral risk factors of the operators during operation will have different degrees of impact on supply chain finance. At present, there is a shortage of professionals who are eligible to carry out supply chain in commercial banks, the professional system learning is lacking, and the business proficiency in low level ${ }^{[3]}$. Managers do not have the capability to prevent high risks and cannot take effective measure to control risks.

Process factors

With complex operating model and various process, supply chain finance also involves numerous participants. Imperfect process design and insufficient execution can be risky. A complete and systematic supply chain operation process is supposed to run through the whole process of pre-credit investigation approval, loan appropriation and post-loan supervision, but China does not have a complete and effective supply chain operation process ${ }^{[4]}$. The reasons are as following, the majority commercial banks only use the electronic platform of supply chain finance, follow the traditional credit business process and framework. The supporting risk control system and technology for the supply chain finance business cannot satisfy the rapid development of business demand ${ }^{[5]}$. There is poor match among different industrial chains, and there is no operational process design that matches the industry chain. Creating a systematic, complete and reasonable internal operational guidelines, building process specifications and risk management organizational structure are urgent actions needed to be executed.

\subsection{Credit risk of supply chain finance}

Supply chain finance business is based on trade in goods and services, the cash flow from trading activities is used as a source of repayment of credit funds, which means the authenticity of the transaction in trade, the fairness of the price and the stability of the value of the subject will affect the credit risk of business. In the actual business, there are collusions between the core enterprises and the suppliers. They acquire bank credit funds by fabricating trade background, excessively exaggerating transaction prices or extending the length of payment cycles, which lead to the misappropriation of credit funds. Internal and external fraud happens.

\subsection{Industry risks in supply chain finance}

Since there are many main participants in supply chain finance, avoiding the credit risk of individual enterprises 
magnifies the market risk brought by cyclical fluctuations in the whole industry ${ }^{[6]}$. When the industry is in a down trend, enterprises in the industry will generally experience higher asset-liability ratio, reduced operating cash inflows and increased debt pressure, and the short-term pressure of each individual enterprise is multiplied by the transmission of the supply chain, which ultimately leads to a chain reaction throughout the supply chain and bring risk to all industries. In addition, the scope of supply chain finance is still in traditional industries. Among the industries that are benefited by supply chain finance business, logistics accounts for a larger proportion, traditional industries like agriculture and environmental protection are not involved deeply in the service of supply chain finance, and banks do not have professional customized services for these industries.

\section{Effective strategy to control financial risks in the supply chain}

\subsection{Practitioners are required to improve their professionalism and capabilities of risk pre- vention}

Compared to traditional credit business, the supply chain finance service provided by commercial banks has more special features. Managers should think comprehensively from multiple perspectives ${ }^{[7]}$. Managers should establish the cognition of systemic analysis and overall control, have the ability to prevent high risk, the ability to judge the reasonableness of financing demand and the ability to determine the legality of documentation business, think from macro perspective, and use efficient information to implement supply chain financial management methods and improve risk control.

\subsection{Establish and improve risk control system}

The risk management of supply chain finance business should focus on the establishment of a comprehensive risk management control system. Different from traditional banking business, it is able to satisfy the increasing supply chain financial business demand by setting up a separate risk management department and rebuilding risk management mechanism $^{[8]}$. In terms of credit risk management, risk control tools, models and concepts should be innovated. Optimize the supply chain financial credit risk management system and set up differentiated risk classification management methods for different types of asset business, in order to match the characteristics of the development of business. By designing scientific and effective comprehensive early warning system for risk of supply chain finance and cooperating with multiple participants, implementing compressive risk control can be achieved. Take full advantage of the internet, artificial intelligence, cloud computing and other high technologies to strengthen the integration of information and technology, increase the information interconnection and audit of enterprises.

\subsection{Focus on industry segmentation, improve business model.}

Commercial banks should carry out professional analysis of industry characteristics and cooperate with ERPf service enterprises. Commercial banks classify products, form differentiated combinations, and identify risks in all aspects. Establish a more complete full range of industry service system, develop professional customized services in non-traditional industries. In addition, since there are many participants in supply chain finance, commercial banks need to develop improved supply chain financial audit access conditions, do research on industry, core enterprises, upstream and downstream enterprises and other subjects, establish access audit standards, improve the capability of risk prevention of supply chain operations and reduce risk of industries.

\subsection{Improve information sharing mechanism}

The improvement of information sharing mechanism is mainly manifested in two points: First is the strengthening of information sharing mechanism between commercial banks and financial supervision and service platform. And the second is the strengthening cooperation among banks. Large banks have a wide distribution of branches, strong financial power. Their scope of services mainly concentrated in large and medium-sized enterprises. While small banks serve and small-sized enterprises, rely on the Internet operation. The differences in customer base between large banks and 
small banks lead to their different business development models. Through the business tween banks, banks are able to take advantage of each other's strengths and expand the scope of their services. Due to market competition, the information sharing mechanism between commercial banks is ineffective, effective channels are lack. Therefore, it is necessary to establish a credit information sharing mechanism for commercial banks to share the important information of supply chain finance subjects and upstream and downstream enterprises without violating the trade secrets of commercial banks, improve the accuracy and real-time performance of information interactions, expand banking services to the periphery of supply chain, which is beneficial to expand the service scope of commercial banks and carry out effective risk prevention and identification ${ }^{[9]}$.

\section{Conclusion}

Supply chain finance is an important method of risk management for capital center, and also an important method for enterprises to finance. With the development of cloud computing and Internet, supply chain finance will develop more rapidly. However, the supply chain financial model still has many risks, attentions are required for the development of all aspects of supply chain finance. It is essential to do a good job in risk management, in order to provide a good environment for the development of supply chain finance.

\section{References}

1. Zheng Z. Research on financing model of small and medium-sized enterprises based on supply chain finance (in Chinese). Journal of Science and Technology Economy 2020; 28(26): 226+152.

2. Zhao Y. Research on the current situation and development countermeasures of supply chain finance business of commercial banks (in Chinese). Liaoning Economy 2020; (9): 16-17.

3. Gao X, Guan Z. Research on optimization strategy of supply chain financial risk control of commercial banks (in Chinese). China Market 2020; (19): 49+51.

4. Zha Z. Research on risks and control measures in supply chain finance of commercial banks (in Chinese). Times Finance 2020; (19): 18-19.

5. $\mathrm{Xu}$ Y. Analysis of commercial banks' supply chain financial mode and risk management (in Chinese). Shandong Economic Strategy Research 2020; (7): 62-64.

6. Yan B, Luo K, Liu L, et al. Supply chain finance: A three-party decision model with suppliers' guarantees for retailers. Managerial and Decision Economics 2020; 41(7).

7. Guo S, Liu N. Influences of supply chain finance on the mass customization program: risk attitudes and cash flow shortage. International Transactions in Operational Research 2020; 27(5): 2396-2421.

8. Gupta V, Chutani A. Supply chain financing with advance selling under disruption. International Transactions in Operational Research 2020; 27(5).

9. Zhu N, Hougaard JL, Yu Z, et al. Ranking Chinese commercial banks based on their expected impact on structural efficiency. Omega 2020; 94. 